\title{
Process Optimization and Experimental Study on the Alkaline Production Process of Potassium Isopropoxide
}

\author{
ZHANG JUNMEI ${ }^{1}$, ZHU AHUI ${ }^{1}$, WANG YAN ${ }^{2}$, HU LINBO $^{3}$, XU WENHUI $^{3}$, DUAN ZHENYA ${ }^{2 *}$ \\ ${ }^{1}$ Qingdao University of Science and Technology, College of Chemical Engineering, Qingdao, Shandong Province, China \\ ${ }^{2}$ Qingdao University of Science and Technology, College of Electromechanical Engineering, Qingdao, Shandong Province, \\ China \\ ${ }^{3}$ Shandong Xinhua Pharmaceutical Co., LTD, Zibo, Shandong Province, China
}

\begin{abstract}
Potassium isopropoxide, involved in the cycle reaction of the intermediate dehydroester, is an important coupling agent in the production of drug pipemidic acid tablets. Current production problems of potassium isopropoxide by alkali method are the long period, the low productivity and the high energy consumption. To solve these problems, the reactive distillation production process of potassium isopropoxide was studied by simulation calculation and pilot experiment. The results show that the production process of potassium isopropanol is influenced by the separation efficiency and the reaction rate. The number of suitable theoretical plates for the column of azeotropic distillation is 14. The dissolution of solid potassium hydroxide is promoted and the reaction rate is increased, when a small amount of water is added to the raw material. It is found that the water content in the reflux organic phase can be reduced by lowering the liquid temperature in the condenser. It is also observed that suitable process conditions and the new type phase splitter can greatly reduced the production time of each batch of potassium isopropoxide.
\end{abstract}

Keywords: potassium isopropoxide, reactive distillation, alkaline

\section{Introduction}

Pipemidic acid is yellowish or faint yellow crystalline powder, odourless and bitter in taste. It has a very good impact on acute or chronic pyelonephritis and bacterial intestinal infection caused by sensitive bacteria. Prahara found that pipemidic acid have a superior analgesic effect [1] than phenazopyridine $\mathrm{HCl}$ and sodium diclofenac in endoscopic urological surgery without serious side effects. Potassium isopropoxide is an important coupling agent in the production of drug pipemidic acid, and it is involved in the cycle reaction of the intermediate dehydroester. The only production facility of potassium isopropoxide was established by Shandong Xinhua Pharmaceutical Co., Ltd. in China in the early 1980s, which provided the raw material guarantee for the production of drug pipemidic acid. However, the original practical problems of long-term reactive distillation $(72 \mathrm{~h})$ and low production capacity have been exposed with the renewal of drug pipemidic acid production processes. Therefore, it is urgent to carry out the optimization research and the design of the original process.

The alkali metal alkoxides, such as sodium methylate, potassium methylate, potassium tert-butoxide, and sodium isopropanol, are important intermediates [2-4] or raw materials [5] in pharmaceutical or chemical production. The production process of alkali metal alkoxides includes metal process, alkaline production process, electrolysis process and so on [6]. Alkali process has the advantages of safe and simple operation and low production cost, so the alkali process has been used in an industrial process [7-10]. The production process of potassium isopropoxide has not been reported in literature. Azeotropic distillation is an effective method for separating azeotropes, such as the separation of methanol and isopropyl acetate [11], acetonitrile dehydration [12], 2-methylpyridine dehydration [13] and acetic acid dehydration [14]. In order to solve the problems of long production time and higher energy consumption, the alkaline production process of potassium isopropoxide was studied by a pilot experiment on basis of the simulated calculation of isopropanol water azeotropic distillation.

\footnotetext{
*email: qust_zyduan@163.com
} 
Potassium isopropoxide can be prepared by the reaction of potassium hydroxide with isopropanol, the equation is as follows:

$$
\mathrm{C}_{3} \mathrm{H}_{7} \mathrm{OH}+\mathrm{KOH} \longleftrightarrow \mathrm{C}_{3} \mathrm{H}_{7} \mathrm{OK}+\mathrm{H}_{2} \mathrm{O}
$$

This reaction is strongly reversible and the rate of the reverse reaction is much greater than the rate of the positive reaction. In order to obtain higher purity potassium isopropoxide, it is necessary to remove the water generated in the reaction in time. Water and isopropanol are azeotropes [15], so the azeotropic distillation dehydration method [16-17] can be used to remove the water from the positive reaction. Benzene, cyclohexane and carbon tetrachloride are common azeotropic agents [18-22] in the industrial production. The boiling point of binary azeotrope of water and isopropanol is $80.3{ }^{\circ} \mathrm{C}$, and the mass ratio of water to isopropanol in the azeotrope is $12.6 / 87.4=0.144$; the boiling point of the ternary azeotrope of water, isopropanol and cyclohexane is $64.3^{\circ} \mathrm{C}$, and the mass ratio of water to isopropanol in the azeotrope is $7.5 / 18.5=0.405$. When the boiling point of ternary azeotrope decreases, the water content is 2.81 times higher than that without azeotrope. Cyclohexane is a suitable azeotropic dehydrating agent [23-24]. The dehydration effect of azeotropic distillation has great influence on the product quality and yield of potassium isopropoxide. Hence, the process of batch azeotropic dehydrating was studied by process simulated calculation in our work.

\section{Materials and methods}

The raw materials used in the experiment are isopropanol (analytical reagent), cyclohexane (analytical reagent) and potassium hydroxide (chemical pure).

The analysis of the product includes the content of free alkali in potassium isopropanol and the content of component in phase splitter. The free alkali (potassium hydroxide) in the product of potassium isopropanol is an important indicator to measure the quality of products. The analysis method of free alkali is as follows: Firstly, the water content in the product is determined by Karl Fischer coulomb titration [26], and then the titrated sample was prepared with benzoic acid $(0.5 \mathrm{~g}$ benzoic acid, $25 \mathrm{~mL}$ anhydrous methanol, $0.7 \mathrm{~g}$ potassium isopropanol sample). Benzoic acid reacts with potassium hydroxide to form water. The free alkali content in the sample is calculated by using the measured water content and the stoichiometric relationship between benzoic acid and potassium hydroxide. The content of components in water phase and organic phase in the phase splitter is analyzed by thermal conductivity cell gas chromatography and quantified by the external standard method.

\section{Results and discussions}

\subsection{Simulated calculation of isopropanol-water mixture separation}

The batch azeotropic distillation dehydration process [25] of isopropanol, water and cyclohexane ternary mixture was simulated by ASPEN. In ternary mixtures, one ternary azeotrope and three binary azeotropes would be formed, and the ternary azeotrope was at the lowest boiling point. The boiling points, and components are shown in Table 1 (computed by the NRTL thermodynamic model in ASPEN). Because cyclohexane and water were immiscible fluids, two liquid phases were formed in the ternary mixture of isopropanol, water and cyclohexane. As a result, the phase splitter was set after the rectification column condenser in simulation calculation of azeotropic distillation, so the organic phase was completely refluxed and the aqueous phase flowed out of the system to be recycled.

Table 1. Ternary azeotrope and binary azeotropes in mixtures of isopropanol $\left(\mathrm{C}_{3} \mathrm{H}_{8} \mathrm{O}\right)$, water $\left(\mathrm{H}_{2} \mathrm{O}\right)$ and cyclohexane $\left(\mathrm{C}_{6} \mathrm{H}_{6}\right)$

\begin{tabular}{ccccc}
\hline Component & $\begin{array}{c}\mathrm{C}_{6} \mathrm{H}_{6}-\mathrm{C}_{3} \mathrm{H}_{8} \mathrm{O}-\mathrm{H}_{2} \mathrm{O} \\
\text { (heterogeneous) }\end{array}$ & $\begin{array}{c}\mathrm{C}_{6} \mathrm{H}_{6}-\mathrm{C}_{3} \mathrm{H}_{8} \mathrm{O}-\mathrm{H}_{2} \mathrm{O} \\
\text { (heterogeneous) }\end{array}$ & $\begin{array}{c}\mathrm{C}_{6} \mathrm{H}_{6}-\mathrm{C}_{3} \mathrm{H}_{8} \mathrm{O}-\mathrm{H}_{2} \mathrm{O} \\
\text { (heterogeneous) }\end{array}$ & $\begin{array}{c}\mathrm{C}_{6} \mathrm{H}_{6}-\mathrm{C}_{3} \mathrm{H}_{8} \mathrm{O}-\mathrm{H}_{2} \mathrm{O} \\
\text { (heterogeneous) }\end{array}$ \\
\hline Azeotropic point $\left({ }^{\circ} \mathrm{C}\right)$ & 64.3 & 68.6 & 68.9 & 80.3 \\
\hline $\begin{array}{c}\text { Azeotropic } \\
\text { composition (molar } \\
\text { ratio) }\end{array}$ & $0.54: 0.23: 0.22$ & $0.61: 0.39$ & $0.7: 0.3$ & $0.67: 0.33$ \\
\hline
\end{tabular}


The following assumptions were made in the calculation model: constant molar liquid holding capacity, adiabatic operation of the tower body, and the tower kettle as a theoretical plate. With the reference to the azeotrope composition in Table 1 and the laboratory experimental data [19], the method of massive excess of isopropanol reactant was considered in the production of anhydrous potassium isopropanol. So the raw material isopropanol, water, and cyclohexane were added to the distillation still in a 10:1:3 molar ratio. The number of theoretical plates in the distillation column with CY packing was selected as 12 . The vaporization rate in distillation still was set as $0.2-0.5$ by setting a fixed heat load at the bottom of the tower. The simulation results are as follows:

The variation trend of the temperature of the tower top and tower kettle with time is shown in Figure 1:

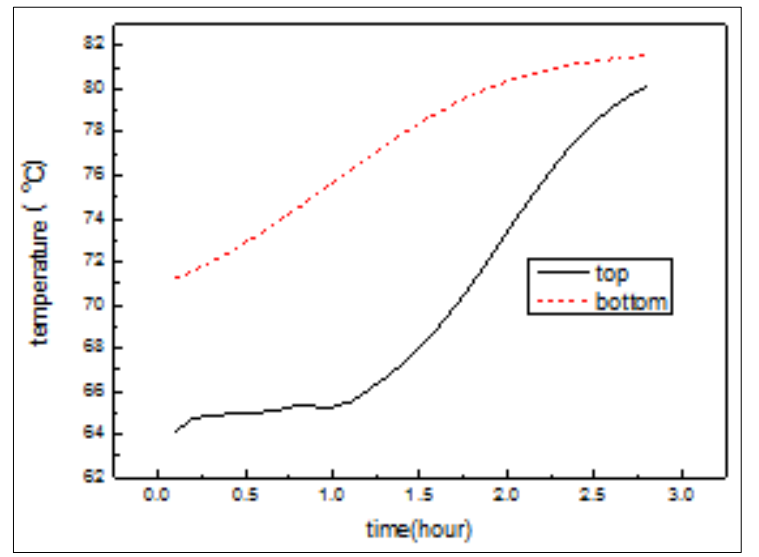

Figure 1. Trend of temperature change in tower top and tower kettle in batch distillation

In Figure 1, the temperature of the tower kettle rises slowly, the temperature of the tower top starts at 64 to $65^{\circ} \mathrm{C}$ and then slowly rises to $80^{\circ} \mathrm{C}$. This phenomenon indicates the following distillation processes: First of all, the water-isopropanol-cyclohexane ternary azeotrope was distilled off at the top of the column, so the water content in the column was reduced. Secondly, the isopropanol-cyclohexane and a small amount of water-cyclohexane binary azeotrope were distilled followed by the isopropanol with higher purity. And then the distillation process ended.

\subsection{Effect of theoretical plate number on water content in distillation still}

The condition for the end of distillation is that the mass percentage of water in distillation still is no more than $0.2 \%$. The total distillation dehydration time required for different number of theoretical plates is shown in Figure 2. The molar ratio of isopropanol, water and cyclohexane is 10:1:3. The packing in the distillation column is CY. And the amount of raw material is a constant.

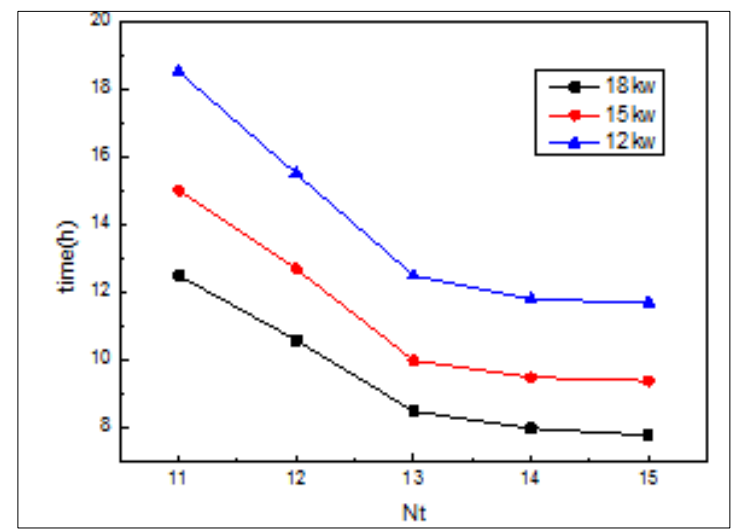

Figure 2. Distillation time required for different theoretical plates 
When the heating power of the distillation kettle is $12 \mathrm{kw}, 15 \mathrm{kw}$ and $18 \mathrm{kw}$ respectively, the relationship between the theoretical number of plates and the required distillation dehydration time is shown in Figure 2. When the number of theoretical plates increases from 11 to 15, the dehydration time first begins to decrease rapidly and then decreases slowly. Therefore, the appropriate number of theoretical plates is 13 or 14 . With the same number of theoretical plates, increasing the heat load can significantly reduce the rectification dehydration time. For example, when there are 13 theoretical plates, the dehydration time of $12 \mathrm{kw}$ heating load is $12.5 \mathrm{~h}$, while that of $18 \mathrm{kw}$ heating load is $8.5 \mathrm{~h}$. As a result, both the theoretical number of plates and the heating power of the tower kettle affect the distillation dehydration time. In the normal gas-liquid contact state (the flooding factor is not greater than 0.7), a large heat load is beneficial to shorten the dehydration time.

\subsection{Effect of initial water content in distillation still on dehydration time}

Potassium hydroxide solids have very low solubility in isopropanol but high solubility in water. A small amount of water in isopropanol increases the solubility of potassium hydroxide in the liquid reactants and the initial reaction rate. The relationship curve between the water content of the tower kettle and the time in the distillation process is shown in Figure 3. The simulated calculation conditions are as follows: the number of theoretical plates in the distillation column is 14 ; the heating power in the tower kettle is constant; the evaporation rate in the tower kettle is 0.6-0.7.

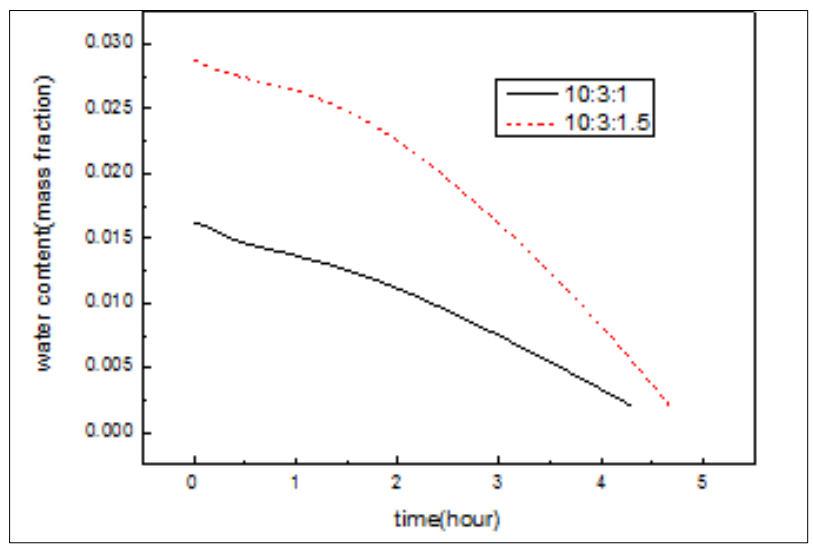

Figure 3. Variation trend of water content in distillation kettle with different initial water content

As shown in Figure 3, the dehydration rate is faster when the initial water content in the reactor is higher. There is no linear relationship between the dehydration time and the initial water content. When the molar ratio of isopropanol, cyclohexane, and water is changed from 10:3:1 to 10:3:1.5, the total distillation time difference will be less than half an hour. In the alkaline production process of potassium isopropanol, a small amount of water can be added to the initial reaction material to promote the dissolution of solid potassium hydroxide and speed up the reaction rate.

\subsection{Effect of cyclohexane dosage on dehydration time}

As an azeotropic dehydrating agent, sufficient cyclohexane is needed to remove water, but excessive cyclohexane would affect the heating load and the separation efficiency of distillation column. When the number of theoretical plates is 14 , the heating power of the tower kettle and water content is constant; the molar ratio of isopropanol to water is 10:1; the variation trend of water content in the tower kettle under different cyclohexane dosage is shown in Figure 4. 


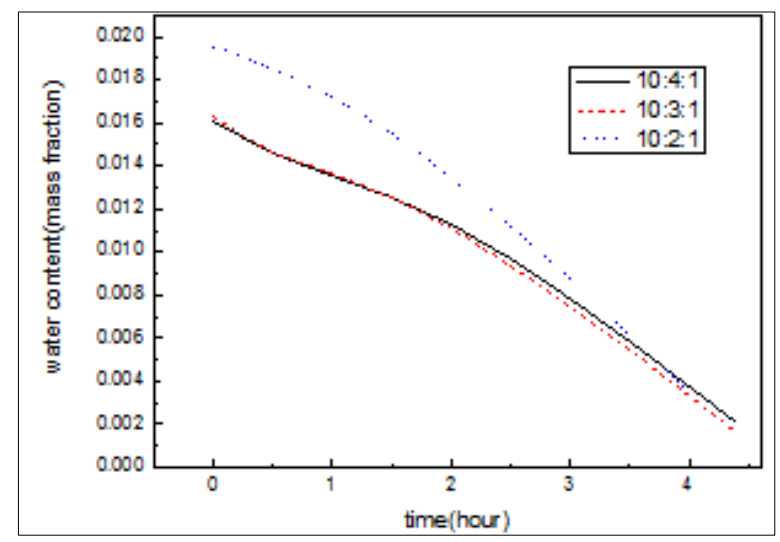

Figure 4. Trend of water content in distillation kettle with different cyclohexane dosage

The molar ratios of isopropanol, cyclohexane, and water in Figure 4 are 10:4:1, 10:3:1 and 10:2:1 respectively. As shown in Figure 4, when the ratio of cyclohexane to water is 2, the water content in the distillation kettle is higher than that at the ratio of 3 and 4 . When the ratio is 3 or 4 , the water content in distillation still is close. However, if the mass percentage of water in the still is no more than $0.2 \%$, the total distillation dehydration time has little difference. So the ratio of cyclohexane to water in potassium isopropoxide production can be selected as 3:1.

\subsection{Effect of condensate temperature on water content in organic phase reflux}

In the production process of potassium isopropanol batch reaction distillation, the ternary azeotrope of isopropanol, water and cyclohexane was distilled from the top of the tower and condensed into the phase splitter. The organic phase in phase splitter flowed back into the tower. The water content in the organic phase also affected the dehydration process of the reaction product. In this paper, the ternary azeotropic composition (molar ratio is 0.54:0.23:0.22) is taken as the raw material composition in the phase splitter, and it is assumed that the Liquid-liquid two-phase reaches phase equilibrium in the phase splitter. The composition of organic phases in the phase division device at $40-60^{\circ} \mathrm{C}$ is shown in Figure 5 .

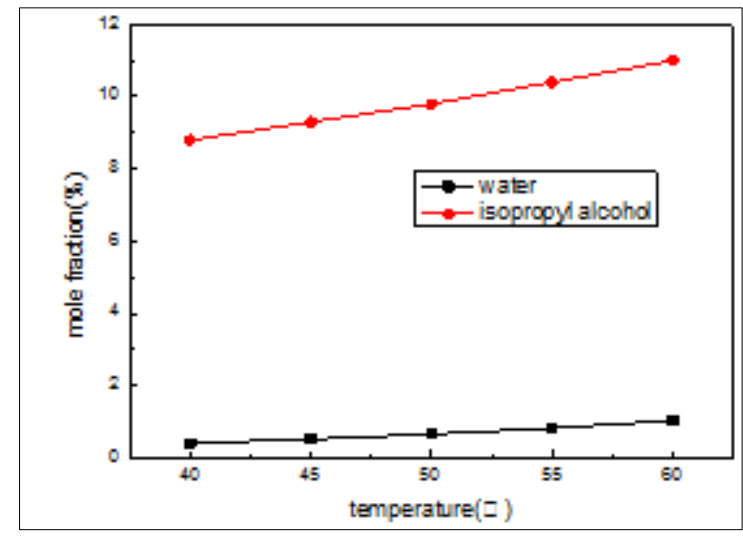

Figure 5. Effect of temperature on composition of organic phase

In Figure 5, the content of water and isopropanol in the organic phase increases with temperature increasing. The molar fraction of water at $40^{\circ} \mathrm{C}$ is $0.4 \%$, and at $60^{\circ} \mathrm{C}$ it is $1 \%$. Lowering the condensate temperature at the top of the column helps to reduce the water content in the reflux liquid. However, the decrease of reflux temperature would increase the thermal load of the tower kettle. So the reflux temperature of the condensate at the top of the tower needs to be determined after comprehensive consideration of energy consumption. 


\subsection{Experimental study on potassium isopropanol in pilot scale}

The pilot-scale experimental equipment includes: a CY packed column with a height of $6 \mathrm{~m}$ and a diameter of $0.4 \mathrm{~m}$, a jacketed stirring reactor with a volume of $1.3 \mathrm{~m}^{3}$, and an ordinary phase splitter with a volume of $0.5 \mathrm{~m}^{3}$. The quantity of raw material for each batch is $700 \mathrm{~kg}$. The schematic diagram of the pilot plant is shown in Figure 6.

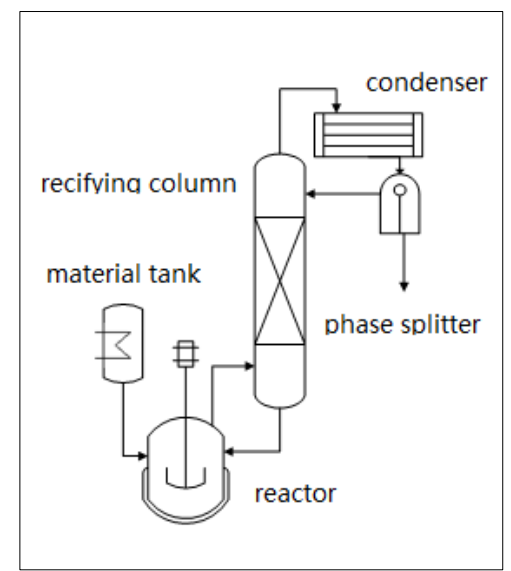

Figure 6. Schematic diagram of the pilot plant of isopropyl alcohol potassium alkaline process

The experimental process is as follows: potassium hydroxide solid $42 \mathrm{~kg}$, isopropyl alcohol $479 \mathrm{~kg}$ and cyclohexane liquid $0.179 \mathrm{~kg}$ were added to the stirred tank to make a mixed solution by stirring. 700 $\mathrm{kg}$ of the mixture was added to the reactor at one time. Steam was turned on to heat the reactor. The temperature was raised and the reaction triggered. The water, isopropanol and cyclohexane in the reaction kettle were heated and boiled, and the azeotropic steam entered the packed column. The top steam of the tower was cooled by the condenser and entered the phase splitter for stratification; the upper layer was the organic phase of cyclohexane containing a small amount of isopropyl alcohol and water; the lower layer was the aqueous phase of isopropyl alcohol and water mixture containing a small amount of cyclohexane. The upper liquid flowed back into the tower, and the lower liquid was continuously put into the alcohol-water storage tank on the premise of keeping the phase interface stable. The isopropanol solution of potassium isopropanol was extracted from the reactor after about $12 \mathrm{~h}$ of reaction rectification time, when the free alkali and total alkali content in the reactor reached the required level.

In the batch reaction distillation process of the pilot test, the water content in the organic phase is analyzed by sampling. The analysis results shows that the water content is $2-4 \%$. And the data in Figure 5 shows that the water content in the organic phase is 0.4 to $1 \%$, which indicates that the content of organic phase water in reflux is much higher than that in liquid-liquid equilibrium. In order to investigate the phase separation effect of the phase splitter, the ordinary buffer tank phase splitter, the internal intubation phase splitter and the new phase splitter [27] are respectively adopted for the experimental research. Experimental results are shown in Figure 7. The new phase splitter, our research groups utility model patent, is a horizontal phase splitter with a built-in corrugated plate group. One end is the inlet and the other end is the outlet. The corrugated plate with small plate spacing and wave height can increase the area of the liquid surface of the two liquid phases, improve the separation efficiency and ensure the stability of the liquid. 


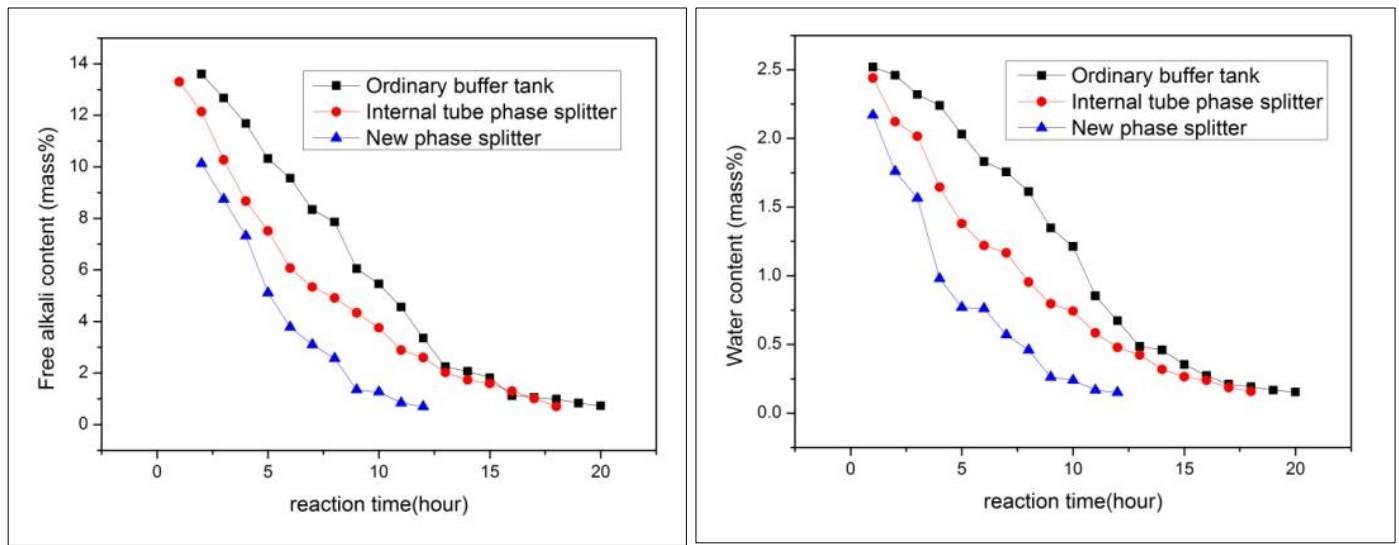

Figure 7. Experimental results of pilot experiment of isopropyl potassium alkaline process

According to the experimental data in Figure 7, the phase separation effect of the phase splitter affects the reaction azeotrope rectification time. The phase separation of the ordinary buffer tank type phase splitter solely relies on gravity sedimentation and would be affected by the feed of the phase splitter. So the reaction dehydration time is the longest. The new phase splitter with internal corrugated plates and independent inlet and outlet positions has the best phase splitter effect. The batch production time of potassium isopropanol is reduced to $12 \mathrm{~h}$ under suitable process conditions and the new phase splitter, which can greatly reduce the original industrial production time. The experiment of optimum development of potassium isopropanol alkali process is successful.

\subsection{Discussion on semi-continuous production process of potassium isopropanol}

Through the optimization of the production process of potassium isopropanol, the production time of a single batch is greatly reduced, but the time of a single batch of reactive rectification still needs about $12 \mathrm{~h}$. If the capacity needs to be further increased, continuous production process can be considered. The reaction of potassium hydroxide with isopropanol to form potassium isopropanol is a strong reversible reaction, while alkali sludge is formed in the reaction process. And the reverse reaction rate is much higher than the forward reaction rate. Semi-continuous production process will be recommended, and its flow diagram is shown in Figure 8. There are two reaction zones in the semicontinuous production process: packing and reaction kettle. The water in the distillation column also helps to dissolve potassium isopropyl alcohol in the isopropyl alcohol solution when the raw material is fed into the column, and the reaction time can be guaranteed by the reaction kettle. The production process is as follows: Isopropanol, cyclohexane and potassium hydroxide with mole ratios of 10:3:1 are put into the reactor as raw materials. After heating, the batch process reaction distillation is carried out until the liquid concentration of the reactor at the bottom reaches the requirements. Then the raw materials are transported to the packed column by the pump. When the free alkali concentration in the reactor is less than $1 \%$, the product is continuously extracted from the reaction kettle quantitatively. Compared with the continuous production process, the semi-continuous production process allows more reaction time, which can ensure the full reaction of potassium hydroxide and isopropanol, or reduce the height of the distillation column. The semi-continuous production process can be considered as the development direction of the potassium isopropanol alkali production process. 


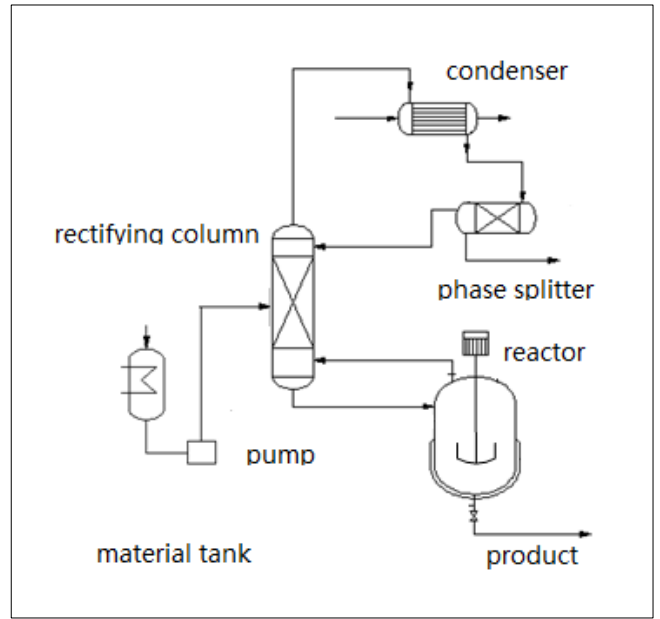

Figure 8. Schematic diagram of semi-continuous production process

\section{Conclusions}

In this paper, including the influence of the amount of cyclohexane azeotrope, the number of theoretical plates in the distillation column and the condensate temperature on the water separation effect of isopropanol, three aspects are investigated through the simulation calculation of isopropanol and water azeotrope separation. The pilot experiment of potassium isopropanol alkaline production is carried out based on the simulation data. The results show that the reaction rectification time can be greatly reduced to $12 \mathrm{~h}$ by adopting appropriate process conditions and high-performance equipment. Specific conclusions are as follows:

(1) In the production process of potassium isopropanol alkali process, the number of suitable theoretical plates for the column of azeotropic distillation is 14. A small amount of water can be added to the raw material to promote the dissolution of solid potassium hydroxide and increase the reaction rate. The water content in the reflux can be reduced by lowering the liquid temperature in the condenser.

(2) Under similar distillation and dehydration conditions, the dehydration time of isopropanol, water and cyclohexane is $4-5 \mathrm{~h}$, and the production time of potassium isopropanol is about $12 \mathrm{~h}$, which indicates that the production process of potassium isopropanol is influenced by the separation efficiency and the reaction rate.

For the alkali preparation process of potassium isopropanol, if considering further reducing the comprehensive energy consumption and improving production efficiency and automation level, the following two aspects need to be done:

(1) The basic data for the reactive distillation process of potassium isopropanol continuous production needs to be studied. The one is gas-liquid phase equilibrium data of isopropanol, water, and cyclohexane liquid in the presence of sodium ions, and the other one is the reaction kinetic equation of the potassium isopropanol reactive distillation and dehydration process.

(2) The semi-continuous production process of potassium isopropanol needs to be studied and developed.

Acknowlwdegement. The research was funded by the Shandong Provincial Primary Research \& Department Plan of China (Grant No.2019GSF109009).

\section{References}

1.YURI P., ALI Z., RASYID N., BIROWO P., Effects of Pipemidic Acid, Phenazopyridine HCL and Sodium Diclofenac on Pain Perception Following Endoscopic Urological Surgery: Double-blinded Randomized-Controlled Trial, Acta med. Indonesiana, 2016, 48(3): 184-192. 
2. YANG X., BAI Y., LI J., LIU Y., PENG J., LI T., LANG R., QIAO B., The catalytic activity of alkali metal alkoxides and titanium alkoxides in the hydrosilylation of unfunctionalized olefins, Phosphorus Sulfur Silicon Relat. Elem., 2019, 194(1-2): 83-86.

3. INAMOTO K., OKAWA H., KIKKAWA S., KONDO Y., Use of tetramethylammonium fluoride (TMAF) and alkali metal alkoxides as an activator for catalytic deprotonative functionalization of heteroaromatic C(sp(2))-H bonds, Tetrahedron, 2014, 70(43): 7917-7922.

4. MANDEA F., JITARU I., OPREA O., ALEXANDRESCU L., Synthesis and Characterization of a New Titanium Alkoxide Used in Anticorrosive Protection, Rev. Chim., 60(6), 2009, 572-576.

5. ZHANG C., YANG J., HU L., ZHANG X., Anionic Copolymerization of Carbonyl Sulfide with Epoxides via Alkali Metal Alkoxides, Chin. J. Chem., 2018, 36(7): 625-629.

6. ZHANG J., FANG L., HU L., Study on the alkaline production process of potassium isopropoxide, Chem. Eng., 2018, 10(46): 74-78.

7. NICOARA A., BADANOIU A., BALANOIU M., MATHIAS A., VOICU G., Alkali Activated Mortars with Intumescent Properties, Rev. Chim., 70(2), 2019, 431-437.

8. STEFANESCU M., DINU L., BUMBAC C., Ultrasonic Alkaline Pretreatment of Biological Activated Sludge from wastewater Treatment Plants, Rev. Chim., 2019, 70(1), 2019, 301-303.

9. PENG H., YANG L., CHEN Y., GUO J., LI B., Recovery and Separation of Vanadium and Chromium by Two-Step Alkaline Leaching Enhanced with an Electric Field and $\mathrm{H}_{2} \mathrm{O}_{2}$, ACS Omega, 2020, 5(10): 5340-5345.

10. STANCIU C., CIUREA A., BUTEICA D., Research Concerning the Use of Synthetic Polymeric Flocculants in Industry, Mater. Plast., 47(3), 2010, 383-391.

11. MISHRA K., KAISTHA N., Synthesis, Design, and Control of an Azeotropic Distillation System for Methanol-Isopropyl Acetate Separation, Ind. Eng. Chem. Res., 2019, 58(3), 1229-1243.

12. JUN Q., LI Y., XUE J., QIAO R., ZHANG Z., Li Q., Comparison of heterogeneous azeotropic distillation and energy-saving extractive distillation for separating the acetonitrile-water mixtures, 2020, 238, DOI: 10.1016/j.seppur.2019.116487

13. CHEN J., YE Q., LIU T., XIA H., FENG S., Design and Control of Heterogeneous Azeotropic Distillation for Separating 2-Methylpyridine/Water, Chem. Eng. Technol., 2018, 41(10), 2024-2033.

14. HUANG X., LI Z., TIAN Y., Process optimization of an industrial acetic acid dehydration progress via heterogeneous azeotropic distillation, Chin. J. Chem. Eng., 2018, 26(8), 1631-1643.

15. WU P., GAO H., SUN J., JI Y., WANG F., GONG C., Characterization of Biomass Adsorbent ZSG1 through Isopropanol and Water Azeotrope Dehydration, Chem. Eng. Commun., 2015, 202(2): 252259.

16. WYCZESANY A., Use of ChemCad simulator for the modeling of isopropanol dehydration by heterogeneous azeotropic distillation, Przem. Chem., 2016, 95(10), 1970-1974.

17. PIENAAR C., SCHWARZ C., KNOETZE J., BURGER A., Vapor-Liquid-Liquid Equilibria Measurements for the Dehydration of Ethanol, Isopropanol, and n-Propanol via Azeotropic Distillation Using DIPE and Isooctane as Entrainers, 2013, 58(3), 537-550.

18. WANG C., Simulation study on intermittent azeotropic distillation of isopropanol-water, Appl. Chem., 2010, 39 (3): 387-389.

19. CHENG Z., MI S., Process design of sodium isopropoxide production by sodium hydroxide method, Med. Eng. Design, 1989, (1): 31-36.

20. ZHU X., WU W., Recovery of isopropanol from aqueous solution of isopropanol by intermittent azeotropic distillation, J. Nanjing U. Chem. Technol., 1998, 20 (3): 71-73.

21. GUO H., FU C., SONG H., Study on the process of separating aqueous solution of isopropanol by batch azeotropic distillation, Nat. Gas Chem. Ind., 2005, 30 (2): 6-10.

22. RODRIGUEZ-DONIS I., GERBAUD V., JOULIA X., Thermodynamic Insights on the Feasibility of Homogeneous Batch Extractive Distillation. 4. Azeotropic Mixtures with Intermediate Boiling Entrainer, Ind. Eng. Chem. Res., 2012, 51(18), 6489-6501.

23. HAN Z., FAN Y., LIU T., Two-Phase and Three-Phase Azeotropic Distillation Investigation in 
Ethanol Dehydration Column, Chem. Ind. Eng., 2015, 32(4), 50-55.

24. GOMIS V., PEDRAZA R., SAQUETE M., FONT A., GARCIA-CANO J., Ethanol dehydration via azeotropic distillation with gasoline fraction mixtures as entrainers: A pilot-scale study with industrially produced bioethanol and naphta, Fuel Process. Technol., 2015, 140, 198-204.

25.NEMETH B., HEGELY L., LANG P., Comparison of batch heteroazeotropic distillation operational strategies for the dehydration of isopropanol, Chem. Eng. Res. Des., 2019, 146, 486-498.

26. WANG A., MAO R., LIANG X., Determination of free base in potassium tert-butoxide by Karl Fischer Coulometric titration, Chem. Anal. Meterage, 2008, 17 (5): 36-38.

27. DUAN Z., DU D., ZHONG G., A horizontal oil-water phase separator. CH2016211277883，201610-17.

Manuscript received: 5.03 .2020 